\title{
Independencia regional, orden político y relaciones internacionales
}

\section{Regional independence, political order and international relations}

Carlos Buller ${ }^{1}$

Academia Diplomática del Perú

\section{Resumen}

Las repúblicas que emergieron de la independencia hispanoamericana conformaron un orden regional caracterizado tanto por la precariedad de sus miembros como por su desventajosa posición internacional. El abrupto colapso de la estructura imperial a la que pertenecieron y la gran transformación de la modernidad, que modificaron los paradigmas globales a los que estos territorios se habían adaptado durante todo el período colonial, se tradujeron en desafíos para los que no estaban preparadas y que amenazaron su viabilidad. Este ensayo ofrece una primera aproximación a esta compleja problemática.

Palabras clave: sistema colonial, independencia, Hispanoamérica, orden político, relaciones internacionales.

1 Doctor en historia por la EHESS. Miembro del Servicio Diplomático de la República y profesor de la Academia Diplomática del Perú. Correo: carlos.buller@gmail.com. ORCID: 0000-0002-3890-7180. 


\section{Abstract}

The Latin-American republics that emerged from Independence formed a regional order characterized by the precariousness of its members, as well as a disadvantageous international position. The abrupt collapse of the imperial structure they belonged to and modernity's great transformation, which modified the global patterns that those territories had adapted to during colonial rule, expressed themselves in challenges they were not prepared for and threatened their viability. This essay offers an initial approach to that complex issue.

Kew words: Colonial System, Independence, Hispanic America, Political Order, International Relations.

\section{Introducción}

En el tiempo transcurrido entre la crisis que sumergió al imperio español en 1808 y diciembre de 1824, cuando capituló el último ejército virreinal después de su derrota en Ayacucho, el paisaje político hispanoamericano cambió radicalmente. Fue una profunda transformación de lo que fue un inmenso espacio sometido al imperio español: una estructura administrativa, fiscal y política de antiguo régimen que, con todo y sus limitaciones, complejidad y contradicciones, había conservado suficiente margen de legitimidad desde la primera mitad del siglo XVI. En menos de dos décadas, este extenso territorio se independizó y se convirtió en un conjunto desigual de repúblicas inexpertas e institucionalmente precarias que pugnaban por sobrevivir en medio de la marea de cambios globales traídos por el parto de la modernidad occidental. 
Estas repúblicas configuraron un orden internacional regional, lo que se entiende como una estructura de relacionamiento entre unidades políticas que guarda equilibrio bajo ciertas formas de legitimidad, reglas y principios aceptados por sus partes, una idea "acuñada por una región o civilización sobre la naturaleza de los acuerdos justos y la distribución del poder" (Kissinger 2014, p. 19). ${ }^{2}$ La teoría clásica plantea que se trata de un medio anárquico en el que estas unidades -los Estados- compiten por su supervivencia y la posesión de recursos, de manera que el conflicto y la guerra serán la expresión natural de estas relaciones, que por tal razón estarán definidas en términos de poder. ${ }^{3}$ Sin embargo, corresponde advertir que una perspectiva así de plana ha generado intensos debates desde las tiendas del constructivismo, el liberalismo y diversas formas de idealismo, entre otras. Estas no ponen el énfasis en el poder, sino en el papel de las instituciones, las normas y las prácticas de gobernanza, entre las que se incluye la personalidad de los mandatarios, dado que, aun si se admite un punto de partida anárquico en el espacio de relacionamiento internacional, la respuesta que los Estados han

2 Recurriré a esta formulación repetidamente y respetaré las comillas en cada caso. Así mismo, utilizaré otros conceptos de la teoría de las relaciones internacionales, como sistema y estructura internacional, íntimamente ligados entre sí, pues "un sistema está compuesto por una estructura y unidades interactuantes" (Waltz, 1979, pp. 79-80). La estructura, al definirse por acuerdo entre las partes, remite de vuelta a la idea de orden. Respecto de las partes, se observará que no siempre cumplen las mismas funciones. Las más poderosas tendrán capacidades sistémicas; es decir, podrán definir la estructura.

3 La teoría clásica es el realismo político, cuyo segundo principio establece que el interés en términos de poder distingue a las relaciones internacionales de otras esferas, como la economía, la ética o la religión, y permite diferenciar entre los hechos políticos y los no políticos. De esta forma, se asume que todo hombre de Estado actuará siguiendo esta pauta fundamental (Morgenthau, 2007, p. 5). 
dado en estas condiciones "nunca ha sido y nunca será una lucha por el poder que esté destinada esencial y directamente a propósitos de supervivencia y seguridad, y ninguna aproximación teórica debería reducirla a ello" (Schroeder, 2010, p. 81$)^{4}$

El orden regional de la independencia se sustentó en los principios que diseñaron el sistema europeo en la Paz de Westfalia de 1648, adaptados a la realidad posrevolucionaria de comienzos del siglo XIX en el Congreso de Viena de 1815. Su estudio implica observar el desenvolvimiento del conjunto, la agenda que propusieron sus miembros y las crisis que enfrentaron. Del mismo modo, permite analizar la función que desempeñó cada uno de ellos y su posicionamiento relativo, es decir, aquel que estas unidades alcanzaron con respecto a las demás: una cosa es que las pautas de legitimidad y relacionamiento hayan sido comunes y aceptadas, y otra -muy distinta- que sus miembros tuvieran las mismas capacidades y se comportaran del mismo modo. En este sentido, asumiendo que se trata de un sistema westfaliano, se podría suponer que las unidades en cuestión habrían actuado siguiendo su propia conveniencia -es decir, el interés nacional-, para lo que habrían utilizado herramientas de poder, como predica la teoría clásica. No obstante, en este caso, se verá que, entre las particularidades del orden regional de la independencia que sirven para relativizar los supuestos ortodoxos, sus miembros expresaron una marcada vocación idealista y trataron de implementar reiteradamente mecanismos de cooperación y solidaridad que no aparecerán en otros espacios hasta más de un siglo después.

4 Se considera, además, que una teoría limitada a los principios westfalianos "no solo es incapaz de entender los sistemas internacionales premodernos, sino que además carece de una perspectiva histórica para dar respuesta, o en algunos casos simplemente abordar, las problemáticas más relevantes del moderno sistema internacional" (Buzan y Little, 2000, p. 3). 
Así mismo, es importante subrayar que, en términos de poder, estas repúblicas no fueron suficientemente capaces de seguir las pautas que caracterizaron a las relaciones europeas en sus luchas por la supremacía. Igualmente, cabe considerar que el orden regional fue una primera instancia de relacionamiento que establecieron estas repúblicas en el marco del sistema internacional global de la modernidad en auge, en el que figuran en una posición periférica, desventajosa y dependiente incluso a nivel hemisférico. Esta circunstancia condicionó fuertemente sus márgenes de acción en los tiempos fundacionales, dada la fragilidad en la que se encontraron durante sus primeros ańos de existencia, su vulnerabilidad frente a la posibilidad de una intervención restauradora externa y la volatilidad de la realidad interna y vecinal de la posguerra.

Estas páginas tienen como finalidad llamar la atención sobre la evolución del orden político colonial hispanoamericano en su tránsito hacia la independencia de sus partes, el resultado de este proceso y los desafíos surgidos durante la configuración de una nueva estructura de relacionamiento regional sustentada en los paradigmas de la modernidad occidental. Siendo este ámbito aún poco explorado, no se podrá llegar más allá de consideraciones preliminares. De hecho, casi toda información en la que se basa este artículo es materia conocida. Sin embargo, intentar una aproximación a esta vasta y compleja problemática histórica utilizando a título complementario algunos criterios y herramientas metodológicas de otras disciplinas - como es, en este caso, la teoría de las relaciones internacionales- podría abrir nuevos horizontes de debate en el contexto del bicentenario de la independencia del Perú que se celebra este año.

\section{Sistema y orden colonial}

La estructura de gobierno impuesta por la Corona española en sus dominios coloniales fue un conjunto acumulativo y 
discontinuo de normas, privilegios, usos y costumbres con estratos de racionalidad disímiles en función del lugar y del momento. ${ }^{5}$ En este laberinto, es posible encontrar en su aplicación, además, un mayor o menor nivel de influencia de elementos originarios, así como comportamientos de evasión, rechazo y resistencia. En su caso, la idea de "la naturaleza de los acuerdos justos y la distribución del poder" que inspiraba este orden estaba definida por un pacto de antiguo régimen que se encontraba muy lejos de configurar un esquema de poder monolítico. Su resultado fue el establecimiento de una monarquia compuesta, cuyos vastos dominios se fueron integrando por diversas vías: la dinástica, la negociación o la conquista. Las dos primeras contemplaban la posibilidad de conservar determinados espacios de autonomía política y judicial, lo que no era factible si se trataba de la última (Schaub, 2015, p. 66). Por lo tanto, las colonias, al ser fruto de la conquista, estaban directamente sometidas a la Corona, que las gobernaba a través del Consejo de Indias. En ultramar, sus autoridades estaban encargadas de administrar, proteger y explotar estos territorios en su nombre, para lo cual se habían implementado rígidos cerrojos monopólicos.

Como se puede apreciar, se trata de un orden que, desde la perspectiva de las colonias e independientemente de las negociaciones que podían producirse en lo alto de la estructura, era cerrado y vertical. ${ }^{6}$ En lo social, estaba

5 No obstante, es preciso reconocer que "en términos de organización burocrática bien desarrollada y profesionalmente dirigida, la España de Felipe II era el Estado más avanzado en la Europa del siglo XVI" (Elliot, 2018, pos. 353).

6 Se debe aceptar la idea de un imperio como un sistema internacional. En el caso de Roma, por ejemplo, se trata "de una fase en la larga historia del sistema internacional del Mediterráneo y del Oriente Medio: una fase en la que la estructura política del sistema toma una forma jerárquica en lugar de una anárquica” (Buzan y Little, 2000, p. 6). 
respaldado por las marcadas diferencias entre sus distintos estamentos -con los europeos en la cima-, situación consagrada por la existencia de dos aparatos jurídicos que diferenciaba a conquistadores de conquistados, conocidos como la república de españoles y la república de indios. Se trataba, además, de un orden corporativo, que negociaba privilegios caso por caso con determinados grupos de interés, no con individuos (Reid, 2017, p. 37). Era un "absolutismo negociado" (Schaub, 2015, p. 73), expresado en el cinismo de expresiones muy familiares, como aquella que proclama con desparpajo que las normas "se acatan, pero no se cumplen". De este modo, se pueden distinguir subórdenes, como aquel correspondiente a la Iglesia y a las congregaciones religiosas, que cobraban diezmos y recibían parte del tributo indígena.

Sin embargo, existían también redes de vinculación paralelas al margen de lo establecido formalmente, distinguibles en una dimensión más amplia e integradora de la realidad colonial, cuyo funcionamiento, visto en conjunto, alcanzaba dimensiones sistémicas. En la práctica, los territorios de ultramar mantuvieron contactos entre sí y con el resto del mundo por medio de una gran variedad de canales alternativos a los establecidos por la Corona. ${ }^{7}$ De hecho, en el terreno, la capacidad del orden colonial para proteger su monopolio fue limitada, y esto se expresa en los altos niveles de autonomía política y racionalidad económica que alcanzaron los distintos espacios regionales y locales. Destaca, así, el poder de los miembros de las élites, que, en

7 Se entiende aquí como orden colonial a la estructura de gobierno formal impuesta por el Estado y al sistema colonial como un todo en el que conviven e interactúan otros órdenes definidos por esquemas de relacionamiento diferentes. De esta manera, aun cuando se puede concebir al orden imperial como el componente estructural del sistema, este no se agota en aquel. 
ciertos casos, llegaron al extremo de absorber a las instancias políticas y administrativas de sus zonas de influencia, las cuales terminarían respondiendo a intereses distintos a los que debían representar. ${ }^{8}$

El orden colonial mantuvo equilibrio, por un lado, gracias a los pactos corporativos y, por otro, gracias al nivel de tolerancia, ineficacia o complicidad que se encontrara del lado formal de la ecuación frente a lo que sucedía más allá de sus esferas de control. De otra manera, es muy posible que hubiera sucumbido mucho antes frente a las tensiones sistémicas: fuerzas que presionaban tenazmente los cerrojos oficiales desde adentro hacia afuera y viceversa. Si bien es difícil medir la real dimensión de esta situación, el peso que llegaron a tener en la dinámica colonial actividades como el contrabando, el fraude fiscal y la corrupción es lo suficientemente revelador como para suponerla enorme, ${ }^{9}$ a lo que se debe añadir la convivencia de una economía monetaria con otra natural, esta última ampliamente extendida en los Andes, ajena a cualquier medio de regulación formal. ${ }^{10}$

8 "Fue así que esa oligarquía [criolla] alcanzó, consolidó y disfrutó en paz, entre 1620 y 1750, su amplia autonomía administrativa, su casi completa autarquía económica y su discreta pero eficaz hegemonía política en las Indias" (Céspedes del Castillo, 1999, p. 144).

9 Se conocen algunas modalidades de fraude a gran escala, como la de la plata "fuera de registro", en la que se involucraron tanto las autoridades coloniales como los agentes comerciales, por ejemplo, los llamados peruleros. Ellos pagaban un $4 \%$ del valor de la carga a los oficiales reales en el Callao y, luego, 2 \% en el Boquerón y Portobelo, de modo que "existían dos redes paralelas en este tráfico: la de la plata registrada y la de la plata por registrar (ilegal), cuyo valor era bastante más alto que el de aquella que entraba por los canales legales" (Suárez, 2009, pp. 274-275).

10 El virrey Francisco de Toledo, en una carta fechada en 1572, señaló que "desde diez leguas de la ciudad de los Reyes acá, no sólo no corre moneda acuñada, pero ni aun un real he visto ni sé que la haya” (R. Levellier, citado por Romano, 1991, p. 243). 
También se debe incluir los altísimos niveles de abuso y explotación sufridos por la población indígena, que fueron mucho más allá de las ya duras normas establecidas para estos fines, así como los nichos de poder -puntuales y limitados, pero existentes- que conservaron algunos miembros de la nobleza indígena, y muchos caciques y curacas, que cumplieron funciones de articulación en los diversos mecanismos de dominio, control y explotación en este enmarañado mundo colonial.

En el siglo XVIII, la Corona hizo un esfuerzo para ejercer el control de sus colonias en esta dimensión sistémica que escapaba de sus manos. Como era de esperarse, las medidas que se implementaron para tal fin generaron un profundo descontento entre los diferentes sectores de la población. ${ }^{11}$ Se produjeron numerosos levantamientos contra "el mal gobierno", la mayor parte de ellos liderados por criollos. Pero la Corona no quiso negociar fueros que no correspondían a estos territorios. En este sentido, importa destacar que, si bien todos los sectores fueron afectados, se podría considerar a los criollos entre los más perjudicados; o, al menos, ellos lo sintieron así, pues fueron sistemáticamente apartados de los cargos públicos, se cambiaron a las autoridades coludidas con ellos, se aumentaron fuertemente los impuestos a sus actividades económicas más rentables, y se diseñaron y renovaron mecanismos de control para limitar su autonomía y evitar la elusión fiscal. La expulsión de los jesuitas y la confiscación de sus bienes añadieron combustible al fuego. Obviamente,

11 "La nueva política en que parecía empeñada la Corona española se basaba en un conjunto de reformas conducentes a hacer saltar el viejo pacto colonial, establecido y mantenido a lo largo de muchos ańos, entre las antiguas autoridades metropolitanas y los poderes locales andinos, cada vez más poderosos, y sustituirlo por una nueva política [...], medidas trazadas en procura de obtener mayores beneficios de los territorios americanos para la metrópoli y sus agentes" (Garavaglia y Marchena, 2005, pp. 31-32). 
estas reformas dañaron seriamente sus bolsillos, pero lo más grave fue que atentaron contra su posición, cuestión muy sensible en los términos del antiguo régimen. El fortalecimiento de la estructura imperial los hizo verse, de la noche a la mañana, sujetos a la autoridad de funcionarios advenedizos que los miraban de arriba abajo. Esto, para quienes se habían considerado los verdaderos amos de las colonias, podría haber alcanzado dimensiones insultantes.

Es posible que, en medio de esta realidad, cuajaran los ánimos precursores que posteriormente alentarían el proceso de independencia. Existen importantes indicios para ello. En efecto, muchos de los levantamientos referidos se gestaron con la oposición entre criollos y peninsulares como telón de fondo, aun cuando en aquella oportunidad no dieron ninguna muestra de buscar una ruptura con la Corona. Sin embargo, el ánimo levantisco de los criollos se vio rápidamente apagado por el temor a un alzamiento general de las poblaciones sometidas. Las experiencias recientes de las matanzas masivas que resultaron de la sublevación de los esclavos en Haití y de la rebelión de Túpac Amaru recomendaban prudencia. Tal parece, pues, que a la larga y aun a regańadientes, los criollos aceptaron las nuevas reglas de juego a cambio de la seguridad proporcionada por la Corona, y fue así como, mal que bien, una calma relativa se esparció por el espacio colonial.

\section{La crisis de 1808}

90 Aquella era la situación cuando, al otro lado del Atlántico, se produjo la abdicación forzada de Fernando VII, cuya consecuencia inmediata fue la virtual disolución del orden imperial español. Se debe recordar que, conforme al pacto de legitimidad de la monarquía española, las colonias no eran posesiones de España, sino de la Corona, por lo que, al desaparecer esta, el derecho a gobernar revertiría a quienes lo habían otorgado originalmente al aceptar el pacto colonial 
(Guerra, 1993, p. 43). Con ello, tanto las fuerzas centrífugas como las tensiones acumuladas desde los tiempos de la conquista en el seno del orden colonial quedarían en libertad, al tiempo que la autoridad de las instituciones de gobierno perdía legitimidad.

La noticia causó una tremenda confusión en las colonias, pues "por muchos años Carlos IV había sido el rey, Francia la aliada y Gran Bretaña el enemigo", y ahora "José era el monarca español, Gran Bretańa la aliada y Francia el enemigo" (Klooster, 2009, p. 130). Pero, pasada la sorpresa -y a pesar del unánime rechazo a la usurpación francesa y las reiteradas muestras de fidelidad al rey depuesto-, las diferencias aparecieron al definir los espacios de autonomía política que cabía reivindicar en cada caso. Como las autoridades coloniales debían su cargo y posición al rey, no estaba del todo claro que su mandato siguiera vigente, lo que abrió un debate político en términos hasta entonces inéditos en las colonias. También propició la aparición de nuevos actores sin mayores credenciales políticas que las otorgadas por su posición social y capacidad económica. En este sentido, se puede decir que la cuestión de quién debía o podía asumir el poder y ejercer responsabilidades públicas se encuentra en el corazón de la crisis que sobrevino en el espacio hispanoamericano como consecuencia de la abdicación de Fernando VII, y sería la que definiría el curso de los acontecimientos posteriores.

Naturalmente, el impacto no fue igual en todas partes. Se dio con mayor fuerza en las ciudades. En ellas, residían las élites, tanto políticas como económicas y religiosas, funcionaban cabildos y tribunales, y eran sede de los diferentes gremios de comercio y minería. También se constituían en los principales centros de ilustración, pues algunas contaban con universidades y prensa, llevaban a cabo debates intelectuales, y organizaban tertulias. No eran urbes muy grandes, lo que facilitaba la interacción social, especialmente entre el segmen- 
to de españoles y criollos, el único con algún tipo de participación en los asuntos públicos. ${ }^{12}$ Eran también ciudades muy desiguales: hacia 1800, por ejemplo, Santiago de Chile contaba con alrededor de 30,000 habitantes y aproximadamente 2,000 casas; la mayor parte era de adobe y solo unas cuantas calles estaban empedradas. Sin embargo, en Chile había 17 mayorazgos y 12 títulos nobiliarios. Aunque la ciudad no contara aún con prensa, la élite organizaba tertulias y la Real Universidad de San Felipe había educado desde 1758 a 1,837 alumnos, entre los que se encontraban 299 doctores en derecho, teología y medicina (Collier y Sater, 2004, pp. 19-21). En Caracas, a mediados del siglo XVIII, el $1.5 \%$ de la población "monopolizaba todas las tierras cultivables y de pastos en la provincia”, y a finales del período colonial, los miembros de la aristocracia rural, que habitualmente vivía en las ciudades, "se mostraban activos en las instituciones que las prácticas espańolas habían abierto para ellos, los cabildos, el consulado y la milicia”. Este sector comprendía 658 familias y un total de 4,048 personas, "o sea, el 0.5 por ciento de la población” (Lynch, 1989, p. 190).

Descontando a las mujeres, los niños y quienes por diversas razones no tuvieron acceso a los cerrados espacios políticos de estas sociedades corporativas, verticales y excluyentes, se desprende que las personas facultadas a participar en un eventual debate político conformaban un grupo muy pequeño. Es decir, las decisiones habrían estado en manos de

12 Según los datos del censo de 1792, la ciudad más poblada del virreinato del Perú era Lima, que tenía una población de 52,627 habitantes, de los cuales 18,047 eran espańoles o criollos. Le seguían el Cuzco, con un total de 31,982 habitantes, y Arequipa, con 23,551. Si bien estas últimas contaban con proporciones más altas de población blanca, los números finales de este segmento poblacional no resultan muy elevados: 15,737 para la primera y 16,122 para la segunda (Vollmer, 1965, pp. 248, 253 y 261). 
unas pocas personas influyentes. De esta manera, la forma de proceder de las diferentes comunidades coloniales hispanoamericanas ante el dilema político que trajo la crisis de 1808 no habría sido el resultado de un sentimiento surgido de las entrañas la sociedad, sino el dictado de estos grupos, los cuales, allí donde les fue posible -es decir, donde las capacidades de la autoridad colonial eran más débiles-, intentaron asumir el control, aun cuando es preciso insistir en que, hasta el momento, seguían sin expresar de manera explícita sentimientos separatistas.

Como se sabe, una parte de las oligarquías coloniales estaba compuesta por funcionarios, magistrados, militares y autoridades religiosas, y la otra, por comerciantes y terratenientes. En principio, se trataba de un grupo conservador, cuyo mayor interés era mantener su posición y privilegios, por lo que, salvo casos individuales, no tenía muchas razones para ver con simpatía alguna la oleada revolucionaria europea. Sin embargo, más allá de esta característica, se debe tener en cuenta que no se trataba de un grupo monolítico. Por el contrario, lo atravesaban profundas divisiones. En consecuencia, para medir la reacción de estas ciudades ante la crisis, conviene evaluar en cada caso la correlación de fuerzas existente al interior de sus élites.

Salvo Buenos Aires, en ninguna capital virreinal se observa la aparición de juntas de gobierno. La excepción bonaerense podría explicarse por ser la cabeza de un Virreinato recién creado en 1774 por la necesidad de fortalecer los controles sobre la mayor ruta del contrabando sudamericano de aquella época, aquella que, partiendo de Potosí, llegaba al Atlántico, justamente en la desembocadura del que, no en vano, se conocía como Río de la Plata. El lugar, además, había sido objeto de un intento de invasión por parte de los ingleses apenas un par de años antes de la crisis española y los vecinos se habían visto obligados a defenderse solos. En tal senti- 
do, no debería sorprender que, en esta ciudad, se acunara el mismo sentimiento que habría alentado a otras ciudades a formar las juntas.

El caso de Caracas vendría a ser más representativo del fenómeno juntista; ahí, la primera reacción ante la noticia de la crisis fue optar por la autonomía. Su relativo aislamiento respecto de los centros de poder y su marcada proyección al exterior lo explican. Pero, aun en esta ciudad, que sería uno de los principales polos revolucionarios continentales, el proceso no transcurrió de manera sencilla. En primer lugar, las autoridades locales pudieron impedir, hasta abril de 1810, la instalación de una junta de gobierno. Además, si bien esta "representaba a la clase dominante criolla", se debe precisar que conforme con lo adelantado líneas arriba- "esta clase no hablaba con una sola voz", pues estaba dividida entre conservadores y radicales, y entre autonomistas e independentistas (Lynch, 1989, p. 194)..$^{13}$ Para reforzar la legitimidad de esta iniciativa, dicha junta convocó a un congreso, que la reemplazó sin haber logrado superar la polaridad cruzada entre unos y otros. Como se sabe, los autonomistas lograron imponerse y Venezuela declaró su independencia en julio de 1811, pero, inmediatamente, se vio sumida en una larga y confusa guerra civil. De hecho, el proceso no se consolidaría del todo sino hasta 1830, cuando se logró separar de la Gran Colombia.

En los principales centros de poder coloniales, las autoridades pudieron imponerse de manera más efectiva gracias a que 94 los sectores conservadores y los peninsulares tenían ahí una

13 Existían, por supuesto, otro tipo de consideraciones: "regiones y grupos sociales en Venezuela, poco o nada ligados al cultivo de cacao, rechazaron a la Junta al estimar que su simple existencia podía provocar el caos en una sociedad donde negros libres y castas de mezcla, en proceso de crecimiento demográfico y de ascensión social, evocaban el fantasma de la espantosa rebelión de Haitî" (Céspedes del Castillo, 1999, p. 375). 
presencia mayor, además de contar con los principales destacamentos del ejército regular. El caso emblemático es el del virreinato limeño, que estuvo en condiciones de emprender campańas para desactivar las juntas de Quito y Santiago, a la vez que trasladó importantes fuerzas al Alto Perú para evitar que la zona minera cayera en manos de las expediciones revolucionarias provenientes de Buenos Aires, a las que derrotó una y otra vez. Este ejército aplacaría también diversos alzamientos -incluyendo la masiva rebelión cuzqueña de 1814-, se impondría sobre las expediciones sanmartinianas a los puertos del sur del Perú y hasta lograría recuperar temporalmente Lima. No sería definitivamente derrotado hasta la batalla de Ayacucho, en 1824.

\section{Prefigurando el orden regional}

La posición adoptada por las distintas colonias hispanoamericanas ante la crisis de 1808 estuvo también vinculada con el lugar que ocuparon en el mapa y el papel que ejercieron en el marco del sistema colonial. Los diferentes niveles de autonomía que alcanzaron determinados espacios tuvieron un correlato en este sentido. En cuanto a las funciones, tenemos, por un lado, a las capitales virreinales y a las sedes de audiencia, que actuaron principalmente como centros de administración y control; por otro, a los puertos, puntos de contacto entre las corrientes de intercambio marítimas, y los espacios de producción y consumo interiores. Por su parte, los centros mineros articularon a su alrededor círculos concéntricos de abastecimiento para poder funcionar, $y$, de este modo, se constituyeron en importantes polos de demanda. Así mismo, de acuerdo con sus posibilidades y recursos, las distintas regiones se especializaron en actividades productivas específicas. Dependiendo del caso, estuvieron más cerca o más lejos del control de las autoridades, y se vincularon o no con vectores de intercambio alternativos a las regulaciones 
monopólicas y con agentes externos al orden colonial. ${ }^{14}$ De esta manera, no cabe esperar que ciudades como Lima, Cuzco, Potosí, Buenos Aires o Caracas reaccionaran de la misma manera ante una situación como la presentada en 1808 .

La exclusividad que le confirió el monopolio comercial y el control de la ruta formal de la plata otorgó a Lima una posición central que la creación de los virreinatos de Nueva Granada (1736) y Río de la Plata (1774) no logró arrebatar del todo. En el primer caso, se debió a que el ámbito de influencia del virreinato neogranadino estaba orientado en otra dirección, al punto de que los espacios amazónicos de Maynas y Quijos -que se pensó que podrían haber sido mejor gobernados desde allí- fueron devueltos a la jurisdicción peruana en $1802 .{ }^{15}$ En el segundo, si bien el Alto Perú pasó a formar parte del nuevo virreinato platense, su vinculación con el Bajo Perú siguió siendo muy estrecha, además de altamente rentable para los negocios y el comercio. Para entonces, además, la minería peruana no dependía únicamente de los yacimientos altiplánicos, gracias a la puesta en producción de

14 El panorama en la costa del Pacífico era más o menos el siguiente: Guayaquil se convirtió en un núcleo que influenció a la sierra quiteńa y cuencana; Tumbes y Trujillo centralizaron la producción regional y el comercio de los valles azucareros del norte peruano; la élite arequipeńa mantuvo sus relaciones con el Alto Perú; Arica fue el puerto de salida y entrada de metales y mercancías (lo que incluía el contrabando); y Chile se fue transformando en una subregión bastante autónoma "que veía al monopolio limeño como una cadena de la que debía librarse cuanto antes" (Garavaglia y Marchena, 2005, p. 43).

15 La Real Cédula expedida el 15 de julio de 1802 dispuso "que la Comandancia General de Maynas, las misiones establecidas en los ríos que desembocan en el Marańón por sus partes septentrional y meridional, y el gobierno de Quijos dependieran en lo eclesiástico y en lo político del virreinato de Lima". Lo mismo ocurrió con la intendencia de Puno, que regresó al Perú en 1796 (Porras Barrenechea y Wagner de Reyna, 1997, pp. 31-33). 
importantes minas en Puno, Arequipa, Cerro de Pasco y Cajamarca, en tanto que el comercio seguía siendo floreciente dentro y fuera del territorio virreinal. En 1808, Lima podía seguir considerándose el centro en más de un aspecto.

Lo que no queda muy claro es si todos los demás espacios podrían ser considerados como periferias limeñas. Esto puede ser incuestionable en los casos de las regiones inmediatamente adyacentes y dependientes de la capital peruana, lo mismo que de aquellas que no estaban lo suficientemente lejos como para escapar a su control directo, como el caso de las provincias del sur del Perú, donde -cabría subrayar- no se apreciaba mucho esta relación. ${ }^{16}$ Ahora bien, si se trata de Caracas o Buenos Aires, resulta un despropósito hablar de periferias limeñas. En el primer caso, incluso resulta cuestionable pensar en estos términos respecto de Bogotá. Caracas, además de ser un importante polo de comercio con proyección hacia el Caribe y el Atlántico, estaba rodeada de un amplio espacio rural donde prosperaban enormes estancias ganaderas, de manera que ella misma actuaba como el centro de un subsistema propio. Lo mismo se puede decir respecto de Buenos Aires: si bien no logró ejercer un control político eficaz en el Alto Perú, gozaba de una gran autonomía, contaba con amplias posibilidades de expansión territorial y controlaba el principal flujo del contrabando que drenaba de las minas altoperuanas, como ya se dijo. En cuanto a otras ciudades con alguna capacidad de articulación de espacios interiores,

16 Entre 1815 y 1820, el Cuzco -donde se había producido en 1780 la gran rebelión de Túpac Amaru- sería "el foco natural de oposición tanto a Lima como a Madrid”, a pesar de haberse creado allí una Real Audiencia. Hubo, luego, propuestas para elevarla como capital del Alto y Bajo Perú. Ideas de esta naturaleza no eran nuevas, pues ya antes se había planteado crear un virreinato o capitanía general en la zona del Collao, demandas dirigidas a "la emancipación del sur del Perú de la ineficiente y costosa maquinaria burocrática de Lima” (Fisher, 1982, pp. 122-123). 
como Quito y Santiago, tampoco podrían considerarse periferias limeñas en sentido estricto, aun cuando, conforme quedó demostrado en los hechos, ambas estaban dentro de los límites en los que el poderoso virreinato peruano podía imponerse con eficacia. ${ }^{17}$

Esto da como resultado un espacio organizado en torno a regiones con niveles de autonomía variable respecto del principal centro de poder colonial, sin que se observe una estructura jerárquica, a pesar de la superioridad relativa del virreinato peruano. Las enormes distancias, las precarias vías de comunicación y los parámetros impuestos por una geografía fracturada serían los factores clave de esta configuración, y definirían luego la pauta del orden regional republicano. Lo mismo se podría decir respecto de la vinculación que cada uno de estos espacios tenía con las corrientes de intercambio transcontinentales, especialmente la del contrabando, en virtud de su aporte a los mercados. Se debe añadir que la dinámica productiva y comercial en el Nuevo Mundo no se limitaba a la exportación de materias primas y minerales, sino que existían polos de generación de riqueza repartidos por todo el continente en torno a diversas actividades productivas. Se trata, por lo tanto, de un esquema policéntrico con subsistemas que se proyectaban más hacia afuera que hacia adentro del conjunto. De hecho, salvo algunos pocos e intermitentes intercambios comerciales recíprocos - muchos de ellos proscritos por siglos en razón del orden monopólico impuesto por la Corona-, entre estos subsistemas no existía

17 La separación entre centro y periferia ocurre cuando "debido a una serie de factores con un origen anterior, una región tiene una ligera ventaja sobre otra en términos de un factor clave, $y$ existe una coyuntura de circunstancias que otorgan a esta ligera ventaja una importancia central en términos de la determinación de la acción social, entonces esa ligera ventaja se convierte en una gran disparidad" (Wallerstein, 1979, p. 138, cursivas en el original). 
ningún otro lazo que no fuera su común subordinación al monarca español y, más tarde, el de una conciencia colectiva de pertenencia a la misma comunidad católica e hispana, la cual, por cierto, no podría considerarse más fuerte que su arraigo regional.

Estos subsistemas eran controlados por las élites de peninsulares y criollos, y, ante la crisis española, predominaría la posición del sector dominante entre ambos. En un extremo, se encontraba la oligarquía limeña, que, por encima de sus diferencias internas, era profundamente conservadora, en razón de que el orden colonial le garantizaba posición y privilegios. De este modo, el virrey Fernando de Abascal, quien rápidamente entendió que su tarea era conservar intactas las posesiones de Fernando VII hasta su retorno al trono, recibió el decidido respaldo político y financiero de la élite limeña en la tarea de desactivar las juntas de gobierno que, si bien no se habían formado en territorio de su jurisdicción, estuvieron al alcance de sus fuerzas (Peralta Ruiz, 2007, pp. 42-143). Muy diferente fue la perspectiva desde fuera, donde el interés predominante iba en el otro sentido, lo que queda claro en los casos de Caracas y Buenos Aires, como se ha visto.

Lo cierto es que en cada región se tejió una historia singular. La junta creada en Quito, una ciudad del interior, expresó interés en alinearse con la junta central española como vía para sacudirse del control virreinal, ya sea desde el Perú o desde Nueva Granada. Sin embargo, la situación llegó a ser tan confusa que hubo quien planteara que "si la España se sugetaba [sic.] a Bonaparte, sería preciso que la América hiciese lo mismo". Resulta, además, revelador que ninguna de las ciudades de su entorno se haya plegado a la iniciativa quiteńa y que, más bien, hayan contribuido con las fuerzas enviadas desde Lima para desactivarla y reprimir a sus líderes (Rodríguez, 2007, pp. 179-181). Esta viene a ser una clara muestra de la variedad de propuestas que podían plantearse en el seno 
de las confundidas comunidades coloniales; a la vez, permite constatar, al interior de los subsistemas identificados, la existencia no solo de posiciones divergentes respecto de la cuestión de fondo, sino también de pugnas entre sus partes y relaciones tensas con sus respectivos centros. ${ }^{18}$

\section{La guerra y la independencia}

El posicionamiento diferenciado de las comunidades coloniales ante la crisis de 1808 se tradujo finalmente en una polaridad que opuso a los procesos revolucionarios de los subsistemas autónomos regionales con el principal centro de poder colonial, el virreinato peruano. Este fue derrotado a fines de 1824, luego de largas campańas militares; de esta manera, se pudo concretar el objetivo emancipador y dar paso al surgimiento de las nuevas repúblicas sudamericanas.

Pero la guerra de la independencia fue mucho más que eso, dado que tuvo múltiples etapas, manifestaciones y escenarios; movilizó ejércitos regulares y mercenarios al lado de milicias, guerrillas y gente común; causó una mortandad que no ha sido adecuadamente calculada, al igual que una devastación enorme, desestructurante y profunda, a una escala que probablemente no había sido vista desde la conquista. A lo largo de su desarrollo, hubo revueltas y conspiraciones, traiciones y cambios de bando, ajusticiamientos arbitrarios, represalias colectivas y matanzas, saqueos, manifestaciones de odio racial e ideológico, y hasta muestras de deshumanización del enemigo. ${ }^{19}$

18 Esta situación la expone muy bien Simón Bolívar en una carta al general Santander fechada en Quito el 6 de diciembre de 1822: "Pasto, Quito, Cuenca y Guayaquil son cuatro potencias enemigas unas de otras, y todas queriéndose dominar sin tener fuerza ninguna con que poderse mantener, porque las pasiones interiores les despedazan en su propio seno" (Bolívar, 1992, p. 210).

19 Durante la rebelión de Túpac Amaru, se registraron casos en los que a los 
El nivel y los distintos tipos de violencia son la mejor expresión de la abrumadora complejidad de la realidad colonial y revelan lo extremadamente tirantes que fueron las relaciones entre los diferentes sectores de la sociedad, más aún si se considera que los episodios más brutales no fueron registrados durante las batallas entre ejércitos regulares. Por ello, sería mejor hablar de una guerra civil continental. De hecho, en ella lucharon americanos en todos los frentes y en todos los bandos, y se podría decir, además, que la violencia desatada no estuvo únicamente destinada a extirpar la presencia imperial española del espacio americano, pues numerosos y enconados enfrentamientos continuaron hasta mucho después de haberse logrado este objetivo.

La sociedad colonial vivía en el límite de la tensión, y el nivel de su resistencia había sido puesto a prueba poco antes con las reformas borbónicas. Como se ha dicho, si bien estas afectaron de manera directa a los criollos, también lo hicieron con los indígenas y demás sectores. En tal sentido, el antecedente de la rebelión de Túpac Amaru, aun sin corresponder de manera directa a la crisis desatada en 1808 , es útil para graficar el nivel de tensión acumulada en el marco del orden colonial: una rebelión que, al inicio, planteó reivindicaciones concretas relativas al reparto y los tributos, se convirtió progresivamente en una cruzada milenarista que incendió el Bajo y el Alto Perú con una violencia inaudita hasta provocar un estimado de 100,000 muertos (Walker, 2014, p. 10), cifra que, para el nivel de poblamiento de entonces, ${ }^{20}$ resulta monstruosa.

cadáveres españoles les extrajeron el corazón y la sangre, que después se consumió. Considerando que en los Andes se condena el canibalismo, "el consumo de partes de los cadáveres españoles debe haber tenido un significado mágico o, de lo contrario, el español no era considerado un ser humano" (Szeminski, 1987, p. 167).

20 Véase nota a pie 12. 
Cuesta explicar cómo se llegó a estos extremos sin aludir a las tensiones preexistentes en el marco del mundo colonial, especialmente considerando que el movimiento juntista, cuyo triunfo "precario y casi siempre fugaz" (Céspedes del Castillo, 1999, p. 373), se había logrado revertir con un saldo relativamente bajo. Además, la promulgación de la Constitución de Cádiz de 1812 había puesto algunos pańos fríos a los espíritus rebeldes con su propuesta marcadamente liberal y la derrota de Napoleón en Europa había fortalecido a las monarquías de antiguo régimen. Pero, aun así, los conflictos se agudizaron. En 1813, Simón Bolívar decretó la "guerra a muerte" en Venezuela, uno de los capítulos más cruentos de todo el proceso independentista en el que se ajustició a cientos de prisioneros y opositores, incluido cualquier español que no apoyara activamente la causa que ya para entonces se había radicalizado considerablemente (Lynch, 2010, p. 98). Del mismo modo, el Perú tuvo que enfrentar rebeliones en Tacna y Huánuco, hasta que en el Cuzco se produjo un nuevo gran levantamiento en 1814, oportunidad en la que se formó una junta de gobierno explícitamente separatista. En aquella oportunidad, se alzaron criollos e indígenas, que tomaron la ciudad y dirigieron su principal esfuerzo hacia el sur con la intención de tomar contacto con las avanzadas rebeldes del Río de la Plata en el Alto Perú. Enviaron, además, una expedición en dirección a Arequipa, que llegó a ser ocupada por los rebeldes durante más de un mes, y otra hacia Ayacucho, en el camino a Lima.

En ambos casos, los rebeldes fueron derrotados, y la experiencia acrecentó una vez más el miedo debido a la violencia desatada, lo que fortaleció a los conservadores y fidelistas. ${ }^{21}$

21 En un caso, con la guerra a muerte, "inicióse una trágica espiral de ferocidad en las batallas y de sangrienta represión en las retaguardias que hasta el momento no había existido" (Céspedes del Castillo, 1999, p. 375); y en el otro, el de la rebelión cuzqueña de 1814, como ocurriera en 1780, 
Casi al mismo tiempo, el desarrollo de los acontecimientos llegó a una encrucijada: el retorno de Fernando VII. ¿¿Regresaría la legitimidad del Gobierno colonial a la Corona restaurada como si nada hubiera pasado? No era lo más probable, pues a pesar de un fidelismo aún muy extendido, a esas alturas las fuerzas sistémicas liberadas por la crisis de 1808 estaban ya trazando su propia historia fuera del marco del antiguo régimen colonial, además de que la Constitución de 1812 había consagrado principios y derechos políticos que reformulaban el pacto imperial. De hecho, se esperaba algo así. Hasta en Francia se habían aceptado algunos hechos consumados por la Revolución (Evans, 2017, pos. 1023). Es muy posible, entonces, que el proceso regional en su conjunto se hubiera desplegado en otra dirección si Fernando VII no hubiera regresado al trono español con la sangre en el ojo y nada dispuesto a negociar. Quiso -literalmente hablandoretroceder el reloj de la historia. Derogó la Constitución Liberal, e impuso un absolutismo reaccionario y vengativo; así, envolvió a España en una renovada espiral de violencia. ${ }^{22}$ En las Américas, la guerra, que parecía destinada a extinguirse, de pronto cobró nueva vida, pues, al cerrarse la posibilidad de una salida negociada para los autonomistas e insurgentes, estos no tuvieron otra opción que seguir hasta las últimas consecuencias.

el conflicto se descarriló y "tomó más el carácter de una lucha racial” (Fisher, 1982, p. 138).

22 "Fuera á la verdad desagradable entrar en mayores detalles de esta guerra feroz, bajo cuyos dolorosos sufrimientos los desgraciados americanos conservaban aún su fidelidad, sin casi ninguna excepción; en la esperanza aunque débil del regreso de Fernando [...]. Puede fácilmente considerarse cuáles serían sus sentimientos cuando vieron que al cabo de tantos sacrificios como habían hecho, este acontecimiento tan deseado, lejos de proporcionar ningún alivio a sus miserias o desgracias, sirvió sólo para que se renovara la opresión y se repitieran escenas y asesinatos aún más horrorosos". (Miller, 1975, pp. 29-30) 
Fernando VII perdió la guerra, porque no tenía la fuerza necesaria para imponerse en todos los frentes que había abierto. No solo España estaba devastada por la larga lucha contra Francia, quebrada financieramente y sin flota, sino que tenía que lidiar con la polarización interna que él mismo había agudizado a su alrededor. De hecho, en 1820, tuvo que enfrentar una fuerte oleada revolucionaria que traería importantes consecuencias en las colonias del otro lado del Atlántico $-\mathrm{y}$ en la que "patriotas y dineros americanos tuvieron sin duda su parte"-, pues, debido a esta coyuntura, un ejército expedicionario en Cádiz listo para ser enviado a reforzar a los realistas sudamericanos jamás se embarcaría; así, dejó a las fuerzas virreinales definitivamente aisladas y a la defensiva, en tanto que el ejército de San Martín, estancado en Chile, obtuvo finalmente la ventaja estratégica y la tranquilidad necesaria para emprender su campaña para liberar al Perú (Céspedes del Castillo, 1999, p. 391).

\section{Orden republicano y caos regional}

El fin de la dominación colonial y la implementación del orden republicano no trajeron la paz al espacio regional, como ya se adelantó. Habría que insistir en que, al desatarse el lazo del control imperial, no fueron únicamente las tendencias autonomistas las que se liberaron. Peor aún: allí donde se formaron juntas, se había desmantelado toda la institucionalidad de gobierno que había regido estos espacios por siglos, y la rápida reversión de estos movimientos impidió que se llegara a establecer un nuevo aparato para tales fines. Consecuentemente, al retomarse la guerra después de la restauración de Fernando VII, los territorios rebeldes no tuvieron otra autoridad que la otorgada por las armas. Esto explicaría en parte los múltiples niveles del conflicto, la diversidad de sus escenarios y lo extremo de sus manifestaciones. También revela que las distintas repúblicas que emergieron vivieran sus primeras décadas en medio de la anarquía y la violencia. 
Un orden republicano implica adoptar un pacto de gobernabilidad sustentado en la voluntad general, la igualdad de las personas, el imperio de la ley y la separación de poderes. De allí su abierta incompatibilidad con el orden colonial de antiguo régimen. No hay que olvidar que, en el marco de este último, los espacios hispanoamericanos estaban sujetos a una monarquía hereditaria que se atribuía un derecho divino a gobernar. Así mismo, cada persona tenía una posición definitiva dada por su nacimiento, raza y condición; existían marcos jurídicos diferenciados; se negociaban privilegios para grupos o estamentos; y los puestos públicos eran asignados a dedo o vendidos al mejor postor. Ahora bien, considerando la profunda raigambre del orden colonial, resulta difícil creer que la sola proclamación republicana y el consecuente cambio decretado en las formas de gobierno hayan sido suficiente para que se operara una transformación similar en las mentalidades, la praxis política y los patrones culturales de las sociedades.

De hecho, no fue así. El establecimiento del orden republicano no bastaría para reagrupar a todos los demonios que se habían desatado y alcanzar, así, un equilibrio político a la altura de sus principios. Además, no conviene obviar el hecho -comprobado a lo largo de la historia desde la caída de Roma hasta la de la Unión Soviética- de que el colapso de un imperio genera una resaca formidable, en la que confluyen el vacío de poder, la desestructuración económica, la conflictividad y la incertidumbre, así como un reordenamiento geopolítico en todo el espacio que alguna vez estuvo bajo su control.

En las colonias independizadas, el aparato de gobierno se desmoronó, los cuadros burocráticos fueron liquidados o huyeron, y el régimen jurídico desapareció. A esto se deben añadir dificultades de otro cuño para la implementación del nuevo régimen, pues el mundo colonial guardaba importantes diferencias con el europeo, en el que se habían gestado 
sus principios e ideario. En las colonias, la realidad estaba estructurada a partir de polaridades inexistentes al otro lado del Atlántico. En efecto, es muy difícil hablar en términos de igualdad ante la ley cuando la organización social se sostiene sobre la base de diferencias raciales, políticas, sociales, y culturales entre conquistadores y conquistados, así como de las que separaban a los hombres libres de los esclavos y de aquellos que estaban sometidos al tributo personal, además de las señaladas entre criollos y peninsulares. En estas condiciones, será difícil construir un Estado nacional unitario en los términos westfalianos, ${ }^{23}$ sin contar las tensiones entre los centros y las periferias al interior de los subsistemas regionales; las rivalidades entre estos y las antiguas capitales virreinales, así como las luchas de poder al interior de las élites, que generaron por doquier fuertes corrientes centrífugas y la aparición de caudillos locales. Tampoco se debe olvidar que la revolución trajo una división intestina entre liberales y conservadores, sumada a un rechazo ventral y fanatizado a todo lo espańol, y al profundo recelo frente a la plebe.

Las consecuencias de la guerra merecen una mención aparte. Primero, por la sangría demográfica, la descapitalización y las deudas. Visto en un sentido amplio, Hispanoamérica venía sufriendo agitación y violencia desde fines del siglo XVIII y su población había sido sometida a constantes levas, decomisos y exacciones de todo tipo, por no hablar de saqueos y destrucción. De la misma forma, las necesidades de defensa, el envío de fuerzas expedicionarias y el mantenimiento de los ejércitos había demandado formidables sumas de dinero a lo largo de este período. Estos esfuerzos dejaron vacías tanto

23 Se entiende que "el nacionalismo es una teoría de la legitimidad política que exige que los límites étnicos coincidan con los límites políticos y, en particular, que los límites étnicos en el seno de un Estado dado [...] no separen a quienes detentan el poder del resto del pueblo" (Gellner, 1999, p. 12). 
las arcas fiscales como las de quienes se vieron en la necesidad u obligación de hacer contribuciones, y un expediente de deudas inmenso, tanto con fuentes de financiamiento externas como internas. Segundo, la parálisis productiva $-\mathrm{y}$ el consecuente colapso de la recaudación- trajo consigo la destrucción de infraestructura, la desindustrialización y el abandono de las minas. Tercero, se produjo la desarticulación del mercado. No se ha prestado suficiente atención a este asunto en particular, a pesar del enorme perjuicio económico causado por la inmovilización de los circuitos comerciales y su correlato en materia de gobernabilidad cuando los múltiples espacios productivos que habían dado vida a la economía de la región durante más de dos siglos quedaron en situación de casi absoluto aislamiento, lo que dejó a su suerte a poblaciones enteras. Esto explicaría -casi tanto como la guerra misma- el ascenso de militares, hombres fuertes y caudillos, quienes impusieron formas de legitimidad carismáticas para llenar el vacío de poder que imperaba en diversos espacios y niveles. Estos personajes lideraron causas locales, regionales y nacionales de carácter populista, reivindicativo y hasta revolucionario, y dominaron la escena política durante el período de transición previo a la consolidación y el fortalecimiento de las capacidades de gobierno del orden republicano. Dejaron para la posteridad una marca de identidad en el quehacer público que se llega a sentir hasta la actualidad.

El obstáculo que representó toda esta situación para las nuevas repúblicas difícilmente puede exagerarse. Cada una de ellas debía enfrentar el pasivo de la posguerra y las demás problemáticas descritas como un requisito para su supervivencia. No todas lo lograron. No hay que olvidar que el Perú terminó mutilado y la que se proyectaba como la más grande y poderosa entre ellas, la Gran Colombia, sucumbió en 1830 y dio lugar al surgimiento de tres nuevas repúblicas, ninguna de ellas ajenas a las mismas circunstancias que propiciaron su creación. Pero la complicada agenda que todas estas repú- 
blicas debían afrontar no se limitó a este tipo de problemas. Su sola aparición en la escena global como unidades estatales que se pretendían soberanas trajo consigo un catálogo inédito de desafíos en el frente externo al que cada una debía prestar urgente atención para evitar, también por este lado, comprometer su existencia.

\section{El marco internacional}

Si bien los cursos de la historia acaecida en Hispanoamérica a raíz de la crisis monárquica española de 1808 encuentran sentido, en gran medida, por los altos niveles de tensión que venían acumulándose en el interior del sistema colonial, no puede en modo alguno soslayarse que el proceso de independencia visto en la escala regional se integra a una transformación mayor que se producía en la escala global. Esta circunstancia sería crucial tanto para el desarrollo de este proceso como para definir la posición que las nuevas repúblicas ocuparían en el nuevo sistema internacional en ciernes.

Precisamente en esos tiempos, el mundo occidental estaba culminando un largo camino, emprendido siglos antes, hacia la modernidad, el capitalismo industrial y la hegemonía planetaria. No existe un consenso para señalar cuándo exactamente se inicia este movimiento histórico de muy larga duración ni cuál fue su primer impulso, dado que, al menos hasta 1800 , no se distingue en el desarrollo de la civilización occidental ningún factor específico capaz de engendrar por sí

108 solo la gran transformación que vivió Europa en el siglo XIX (Pomeranz, 2000, p. 32). Sin embargo, no cabe duda de que haber dispuesto de manera exclusiva de la riqueza humana y natural del Nuevo Mundo contribuyó al desarrollo de este proceso de modo sustancial. Por un lado, se vio favorecido por la posibilidad de explotar la mano de obra, la experiencia y los conocimientos de las altas civilizaciones originarias a las que los europeos sometieron. También contribuyeron 
las intensas dinámicas económicas articuladas en torno a la pesca, la exportación de pieles y maderas, el cultivo de azúcar, tabaco y algodón, entre otros, que catapultaron la generación de riqueza y animaron todo tipo de intercambios en el espacio atlántico, pero, además -y quizás en mayor medida-, por tener a disposición una riqueza mineral inaudita. Gracias a la plata americana, Europa estuvo en condiciones de controlar las transacciones globales, imponer nuevos paradigmas de negocios y desarrollar la banca y las finanzas; de este modo, se sentaron las bases de su futura supremacía planetaria. ${ }^{24}$

Sin embargo, este desarrollo no fue liderado por España, que quedó a la zaga de la evolución de sus rivales. Sus propias colonias la superaron en dinamismo, ya que lograron tempranamente un amplio margen de autosuficiencia económica (Lynch, 1989, pp. 10-11), al punto de que, en determinado momento, llegó a decirse que "España era la colonia de sus colonias" (Braudel, 1979, p. 500). Por ello, se puede considerar que, en el orden internacional global, las economías coloniales estuvieron posicionadas como variables con capacidades de influencia sistémica, pues lo que ocurriera o dejara de ocurrir en ellas podía tener consecuencias insospechadas en diversas partes del planeta. ${ }^{25} \mathrm{El}$ pulso vital de ciudades-

24 Se puede constatar que la economía europea retuvo una cantidad de plata igual o incluso superior que los mercados orientales. Se estima que, entre 1600 y 1650, la cantidad anual de plata que absorbió Europa fue de 158,5 toneladas en comparación con un rango variable de entre 91 y 126 toneladas en Oriente, mientras que, en el período 1725-1750, estos montos habrían aumentado a 230 toneladas para Europa y de 175 a 211,2 toneladas para los mercados orientales (Jan de Vries citado por Findlay y O'Rourke, 2009, p. 218).

25 El caso más notable es el de los reales de a ocho, acuñados con la plata americana, cuya cantidad y difusión hizo posible el desarrollo del comercio internacional entre los siglos XVI y XVII. Pero estas monedas también generaron alteraciones, a causa de los fraudes en los que se podía 
mundo como Sevilla, Londres o Amsterdam dependía de la llegada del tesoro americano y demás productos de alto valor de intercambio provenientes del otro lado del océano.

En términos de larga duración, España era la potencia sistémica en declive e Inglaterra la que lideraba la transformación (Marks, 2007, pp. 120 y 139). No obstante, en el marco de este proceso de cambio surgió un elemento desestabilizador: la revolución. Recordemos que, si bien el mundo occidental estaba transformándose, los vectores de cambio eran todavía poco representativos de la realidad de aquellos tiempos. Los países aún estaban gobernados por monarquías hereditarias, y las relaciones políticas y sociales seguían estructuradas por los paradigmas tradicionales de antiguo régimen. La inmensa mayoría de las personas vivía en contextos rurales locales y en condiciones de subordinación o servidumbre, se desplazaba poco, y estaba fuertemente apegada a la tierra. No obstante el gran desarrollo del comercio, la economía seguía siendo esencialmente agraria y esta no había cambiado mucho desde el neolítico. Del mismo modo, a pesar de existir algunas ciudades densamente pobladas y de la creciente importancia de la burguesía, la mayor parte de personas que habitaba contextos urbanos residía en pequeños núcleos poblacionales de apenas unos cuantos miles de habitantes, "ciudades en las que un hombre podía trasladarse en cinco minutos desde la catedral, rodeada de edificios públicos y casas de personajes, al campo" (Hobsbawm, 1991, p. 17).

110 Pero el tremendo peso de lo tradicional hizo que las vanguardias de la modernidad se alejaran cada vez más de esta reali-

incurrir al acuñarlas. De hecho, se sabe que, entre 1630 y 1650, la ceca de Potosí inundó el mundo con enormes cantidades de monedas falsas, lo que trajo problemas no solo en Sevilla, sino también en plazas comerciales tan diferentes como Nantes, Konigsberg o Génova (Cipolla, 1999, pp. 112-116). 
dad estática y los estirados lazos que las unían llegaran a un punto de ruptura. El hecho de que la mayor fractura se diera en Francia representó un tremendo desafío estratégico para Inglaterra, de modo que el ya viejo conflicto entre ambas potencias adquirió una nueva dimensión. No es que Inglaterra se erigiera como la campeona de las fuerzas tradicionales, sino que la revolución amenazó con romper el equilibrio continental. Pero la Francia revolucionaria había planteado una guerra contra todas las monarquías hereditarias, lucha que transgredía de manera flagrante los principios westfalianos al buscar su derrocamiento, un conflicto que, por su propia naturaleza, no contemplaba una solución de compromiso, sino la victoria total. ${ }^{26}$ En caso de ganarla, entonces, todo el sistema europeo por el que velaba Londres se vendría abajo. Consecuentemente, también desde el punto de vista inglés, no había otra alternativa que destruir a su enemigo. Esta guerra duró más de veinte años y comprometió a todas las potencias europeas. Al final, a pesar de no haber liquidado del todo el desafío revolucionario -que aun debilitado permanecería vigente y quizás también más extendido-, tanto el mapa como el orden europeo habían cambiado, y dejaron un paisaje desolador de parálisis y destrucción (Evans, 2017, pos. 435-611).

El fin de la guerra trajo consigo, además de esta gran devastación, importantes consecuencias políticas en Europa. Por un lado, se encuentra una pausa revolucionaria y el fortalecimiento de las monarquías hereditarias europeas. En este marco, destaca el surgimiento de Rusia como la principal

26 La Revolución francesa "fusionó la política interior y la exterior, la legitimidad y el poder, cuya previa división por el orden westfaliano había limitado el alcance y la intensidad de las guerras en Europa. La concepción de un orden internacional que imponía límites a la acción del Estado fue abandonado a favor de una revolución permanente que solo buscaba la victoria o la derrota absolutas" (Kissinger, 2014, p. 43). 
potencia conservadora en el continente, promotora de una Santa Alianza destinada a mantener el orden y a intervenir allí donde fuera necesario para eliminar cualquier foco revolucionario. Por el otro lado, se observará la reconfiguración del orden europeo conforme a los términos de la Paz de Viena, mediante los cuales se trató de establecer un equilibrio continental. Para tal fin, se sustrajeron territorios a Austria y Francia, se promovió el fortalecimiento de Prusia y se crearon "Estados-tapón", entre otras regulaciones por el estilo. Se esperaba, de esta manera, que las potencias se neutralizaran entre sí para garantizar la paz, aun cuando, en la práctica, estas medidas posicionaron a Inglaterra y a Rusia como actores prácticamente invulnerables, ventaja que aprovecharon para expandirse en sus respectivas áreas de influencia: la primera, en los mares, y la segunda, en el amplio espacio continental euroasiático (Schroeder, 2004, p. 40).

\section{Posición internacional regional}

El resultado de esta evolución definió los términos y el carácter del orden internacional en el que se inscribirían las nuevas repúblicas hispanoamericanas. Tanto la estructura funcional como la organización sistémica y lo que arriba se ha definido como "la naturaleza de los acuerdos justos y la distribución del poder" que surgió de los acuerdos de Viena configuraron una nueva realidad en la que estas repúblicas -con todas sus limitaciones y problemas no resueltos, y en plena bancarro-

112 ta- debían aprender a andar, sobrevivir y prosperar como entidades soberanas.

Esta realidad no era amistosa. Por una parte, por su propio origen revolucionario, los países recién independizados enfrentaron un entorno internacional marcadamente hostil en los albores de su existencia. El triunfo de la restauración monárquica en la Europa posterior a los acuerdos de Viena las convirtió en elementos políticos indeseables para algunos 
actores sistémicos centrales, al punto de que se llegó a barajar la posibilidad de intervenir en Latinoamérica para salvar los imperios coloniales ibéricos. ${ }^{27}$ Por otra parte, la supremacía británica, sustentada en su victoria sobre Francia y un equilibrio europeo favorable, además de su acelerado desarrollo industrial y el control casi absoluto de los mares y del comercio internacional, puso a todos estos países en una posición de inapelable inferioridad y virtualmente a merced de la potencia que había sido rival tradicional de la antigua metrópoli. ${ }^{28}$

Sin embargo, lo que se podría considerar aún más grave es que, debido a las transformaciones de la modernidad, se había perdido la posición que todos estos espacios habían disfrutado desde su incorporación a las corrientes globales de intercambio en el ya lejano siglo XVI. En la nueva configuración internacional, las repúblicas independientes hispanas surgieron como variables marginales. El mundo en el que las riquezas coloniales gozaron de una alta demanda en la escala global y estuvieron en el centro de las disputas entre las grandes potencias había quedado en el pasado. ${ }^{29}$ Si bien las

27 Esta posibilidad fue del todo descartada luego de la promulgación de la Doctrina Monroe en diciembre de 1823, por medio de la cual Estados Unidos se comprometió a impedir cualquier intervención europea en los asuntos americanos (Evans, 2017, pos. 933).

$28 \mathrm{La}$ fórmula tradicional que señala que las colonias hispanoamericanas cambiaron una dependencia por otra debe revisarse. En el caso del Perú, por ejemplo, las condiciones internas, el caos y la inestabilidad actuaron "como una coraza frente a las pretensiones del imperialismo no solo británico, sino también francés y norteamericano, cuyos tentáculos no hallaban cómo asir una materia tan escurridiza e impredecible”, además de que el carácter de su política de comercio exterior "no fue la de una desaforada apertura hacia el mercado mundial, como había sostenido la teoría de la dependencia, sino el proteccionismo" (Contreras, 2004, pp. 28-29).

29 El peso de la economía de las colonias hispanoamericanas se expresa en que, hacia 1785, exportaron a Europa 63,3 millones de pesos entre me- 
exportaciones de productos como el algodón, el azúcar o el tabaco mantuvieron su presencia en los mercados, la Revolución Industrial y el auge del capitalismo estaban cambiando la racionalidad de la economía global y otorgando mayores márgenes de ganancia al valor agregado, la innovación y la producción de bienes de consumo a escala; ello abarató costos y desplazó sin contemplaciones a los sectores que no pudieron competir. El caso de los textiles es emblemático. Si bien el proceso más dramático de desindustrialización textil se dio en la India y en el sudeste asiático, interesa constatar que, hacia 1820, Latinoamérica compraba alrededor de la cuarta parte de la producción inglesa y, para 1840, esta proporción había aumentado a la mitad (Stearns, 2013, p. 29). Es posible imaginar el impacto de esta situación sobre los espacios tradicionales de producción textil como Quito y Huamanga.

El caso de la plata merece mención aparte. Este metal llegó a ser el medio de cambio preferido para las transacciones comerciales internacionales, ya que todo se podía comprar con él, al extremo que, hasta en nuestros días y en más de una lengua, se utiliza la palabra plata como sinónimo de dinero. Por tal motivo, durante el período colonial, los yacimientos minerales de México y Perú atrajeron a las corrientes económicas internacionales de mayor caudal, y ubicaron a estos territorios como una variable sistémica esencial. Pero en los albores republicanos esto era también cosa del pasado. Debe recordarse que, hasta el siglo XIX -es decir, cuando los efectos de la Revolución Industrial empezaron a sentirse en la

tales preciosos y otros productos, en tanto que sus importaciones fueron 38.3 millones de pesos. El desbalance es claro, incluso sin considerar el aporte del Brasil, con el cual la diferencia sería de unos 30 millones, un monto no inferior a 6 millones de libras esterlinas. Esta cifra quintuplica los beneficios que se obtenían de la India, cuya población era, a su vez, 5 veces mayor que la latinoamericana (Braudel, 1979, p. 527). 
escala global-, Europa no contaba con ningún producto que impresionara a los exigentes y sofisticados mercados orientales, de modo que todas sus compras las debían pagar en metálico, situación que se traducía en una balanza de pagos intercontinental permanentemente deficitaria. La demanda de plata en China y el descubrimiento de los fabulosos yacimientos americanos hicieron posible estabilizar la situación y mantener un ritmo creciente en los intercambios por más de dos siglos. Esto cambió con la industrialización y sus secuelas. Diversos productos de bajo costo empezaron a inundar también los mercados orientales y el último reducto, la misma China, fue desbordada después de las guerras del Opio. A partir de entonces, el circuito de la plata cambió de sentido y este metal empezó a fluir en dirección contraria. ${ }^{30}$

Hacia la primera mitad del siglo XIX, estaba terminado el gran ciclo de la plata de la economía global. Por si fuera poco, la minería estaba casi paralizada y su declive se había llevado a todos aquellos sectores que, de alguna u otra forma, integraron los círculos de abastecimiento que la hizo funcionar. Para el Perú, esto se convirtió en un fallo estructural que condujo a la reorientación de la economía, cuyo eje se desplazó de la sierra a la costa en un contexto de fragmentación espacial. Esta situación, no del todo ajena a los demás países,

30 Como quiera que "los pianos y relojes no despertaban demasiado interés en China”, hacia comienzos del siglo XIX, la Compañía de Indias Orientales, el gigante comercial inglés, seguía pagando sus importaciones con plata, situación que se agudizó cuando en Inglaterra se empezó a consumir té en grandes cantidades. Entonces, apareció el opio de la India como una alternativa eficaz. Las ventas de esta droga se dispararon desde 1815, al punto que quince años más tarde la plata empezó a salir de China a razón de 34 millones de onzas anuales. En razón al consumo de 40 millones de adictos, se ha afirmado que "la demanda de opio en China durante el siglo XIX estimuló la actividad económica mundial [y] a medida que el opio entraba en China, la plata salía” (Marks, 2007, pp. 169-173 y 185). 
se sumó a la compleja problemática interna de la posguerra descrita. De este modo, se puede afirmar que toda la región se integró al sistema internacional del siglo XIX en condiciones muy desventajosas, lo que condicionaría fuertemente sus posibilidades de progreso en el futuro.

\section{El orden internacional regional}

Los subsistemas de desarrollo autónomo identificados en el marco del orden colonial sirvieron de base territorial para el surgimiento de las repúblicas independientes. Su viabilidad política dependió, en gran medida, del nivel de control que los respectivos centros tuvieran sobre los espacios interiores, que hacían las veces de sus periferias. La dispersión centroamericana y el colapso de la Gran Colombia son los mejores ejemplos de lo que podía ocurrir sin la existencia de un centro de poder capaz de ejercer tal función. Es también el caso de la inestabilidad interna que vivió el Perú como consecuencia de la separación de Bolivia y el marcado rechazo de las provincias del sur hacia la supremacía limeña. ${ }^{31}$ Incluso en un espacio más pequeño, como el de la república ecuatoriana, surgida en 1830 como resultado del colapso grancolombiano, se presentaron tensiones entre la costa y la sierra, y aun entre ciudades tan cercanas como Quito, Cuenca y Loja. Menos complicados podrían considerarse los casos de Caracas, Buenos Aires y Santiago de Chile, que, más allá de los debates internos y polaridades ideológicas que pudieran haberse suscitado, no tuvieron mayor problema en ejercer el control

31 En el Perú, "las regiones fronterizas hesitaron respecto de sus filiaciones, caso de Guayaquil, Jaén o Puno. La creación de Bolivia, el antiguo Alto Perú, como un nuevo país, en 1825, aumentó la confusión y las opciones que tenían por delante regiones como Puno, el Cuzco y la misma Arequipa. Evidentemente, competir por la centralidad política con La Paz o Sucre podía ser mucho más fácil para ellas que competir con una ciudadpuerto como Lima” (Contreras, 2004, p. 278). 
político de sus respectivos espacios de influencia; incluso, estuvieron en condiciones de emprender una expansión hacia los llanos, la pampa y la araucanía, respectivamente.

Todos estos países, además de consolidar su viabilidad hacia adentro, debían definir sus respectivos territorios y diferenciarse del resto. La herencia colonial condicionó esta tarea. Ellos habían conformado, hasta poco años antes, una misma comunidad política, cultural y religiosa, y tenían que aprender a verse como entidades soberanas distintas, cuyos asuntos eran ahora ajenos. Debe tenerse en cuenta que, en los primeros años, llegó a ser corriente tener gobernantes, cancilleres, ministros y generales de diversas procedencias. ${ }^{32}$ Pero eso ya no podía continuar. Era preciso sentar las bases de lo nacional, de sus símbolos y representaciones, así como crear un relato de respaldo. Del mismo modo, cada una de estas unidades políticas debía también definir intereses y objetivos propios, y buscar los medios y capacidades para cumplirlos.

Las nuevas repúblicas empezaron su vida internacional estableciendo relaciones entre sí. Casi inmediatamente después de su creación, estos países se enviaron embajadas y firmaron acuerdos. Lamentablemente, esta no fue la única vía por medio de la cual se fueron armando las bases del orden internacional regional: fue inevitable el surgimiento de disputas en materia de deudas y límites: alguien tenía que hacerse cargo de los costos de las campañas militares y de las deudas asumidas para su despliegue. En el caso del Perú, cuya liberación material vino de afuera, debía arreglar estos desagradables asuntos con Chile y la Gran Colombia. Respecto de los lí-

32 Juan García del Río, un político y escritor colombiano, fue, por ejemplo, jefe de Gobierno y embajador de la Gran Colombia, canciller de Chile, del Perú y de Colombia, y ministro de Hacienda en el Ecuador y en el Perú. Murió en 1856 en México, donde fue asesor de Antonio López de Santana. 
mites, es muy conocida la confusión que se generó. Se suele achacar a una ineficiencia del orden colonial la inexistencia de una demarcación clara entre sus distintas circunscripciones administrativas, lo que sería el factor determinante de los largos y complejos desacuerdos limítrofes entre las repúblicas sudamericanas. Esto es en gran parte cierto, pero, al mismo tiempo, se debe admitir que, al interior del Imperio español, no era necesario establecer límites tan precisos. Además, se deben considerar las tremendas dificultades y costos que podía representar emprender tal tarea, que, en términos prácticos, resultaba en muchos casos inútil, dado los inmensos espacios que ni siquiera estaban ocupados por las autoridades coloniales. No obstante, esta era la realidad: ahora sí era preciso establecer estos límites y los países, obviamente, partieron de posiciones maximalistas.

Aunque suene controversial, es justo reconocer que, por encima de todas las consecuencias de estas diferencias, en el marco del orden internacional regional de la independencia, primó la voluntad negociadora. De hecho, se debe admitir que los desacuerdos más graves y las guerras que corresponden a este período fundacional están más relacionados con las disputas entre las regiones interiores y las ambiciones de los caudillos que con los problemas señalados. Aún más, respecto de la difícil problemática limítrofe, merece destacarse el consenso voluntario alcanzado entre todas las partes para establecer dos criterios de base para estas negociaciones: el uti possidetis (o de los títulos coloniales), que otorgaba el reconocimiento del Estado posesorio en que se hallaban las provincias o regiones coloniales y la continuidad de estas en favor de las repúblicas independientes considerando como año base 1810, y el de la libre voluntad de los pueblos, que lo complementaba (Porras Barrenechea y Wagner de Reyna, 1997, pp. 35-36). Un arreglo de principio de esta naturaleza dice mucho de la visión de los primeros estadistas de la región, que no ha sido suficientemente valorada. Por el contra- 
rio, se ha puesto un marcado énfasis en los conflictos, como si fuera una falla de origen de las repúblicas hispanoamericanas sin considerar cuál hubiera sido el rumbo de la historia sin estos acuerdos elementales, adoptados en el marco del extraordinario universo de dificultades que envolvió este período de aprendizaje y el contexto de tensiones desatadas del orden colonial.

Hubo guerras internacionales importantes, sin duda. Pero en su origen se encuentra otro tipo de factores. Desde la perspectiva estratégica, uno de los focos de conflicto fue la separación del Alto Perú para la creación de Bolivia. En razón de su extraordinaria riqueza mineral, este territorio fue el earthland del sistema colonial y hacia él convergieron intereses de casi todo el espacio subcontinental, especialmente del Bajo Perú, que lo abastecía prácticamente de todo: insumos, alimentos, estimulantes, bienes de lujo importados, entre otros. Era un sistema que funcionaba gracias a la integración de todas estas corrientes. Separarlas fue un evento traumático para unos y otros. En lo que fueron el Alto y Bajo Perú, generaron diversos intentos de reunificación provenientes de ambos lados, lo que representaba una amenaza para la posición de Lima y una posibilidad que tampoco interesaba en Chile, donde existía el temor de no seguir en una posición periférica en el extremo sur del continente si se volviera a consolidar una potencia superior por el norte. Aparecieron así tensiones de carácter geopolítico, y los recurrentes conflictos en esta zona confluyeron a fines de la década de 1830 , cuando una alianza entre peruanos y chilenos destruyó a la confederación que el gran caudillo boliviano, Andrés de Santa Cruz, intentó consolidar sobre la base de la reunificación de todo el sur andino. ${ }^{33}$ Como se sabe, estos mismos países se

33 En una forzada aplicación de los términos del realismo político, Robert Burr calificó a Chile como "el campeón del equilibrio americano" por su acción en contra de la Confederación Perú-Boliviana, cuando en ella 
comprometerían, luego, en una guerra mucho mayor, lo que permite deducir que las cuentas pendientes de los tiempos fundacionales no habrían quedado del todo saldadas en esta oportunidad.

Un último aspecto que se debe tener en cuenta respecto de la problemática de la demarcación limítrofe -y que, sin duda, debió complicar las negociaciones- es el que yace en el ámbito de las relaciones transfronterizas. Se trata de un tema aún poco explorado, pero se sabe que hubo espacios donde los límites entre las distintas unidades administrativas coloniales no correspondían con la integración realmente existente entre la población de ambos lados de la línea, una situación nada sorprendente si se considera que todas ellas formaron parte de un mismo territorio imperial y de una vasta área cultural anterior. El caso más notorio es, indudablemente, el que se acaba de presentar, entre el Alto y el Bajo Perú, que incluye la realidad de comunidades nativas en constante interacción de un lado al otro, pero no es el único. De hecho, el mismo espacio altoperuano tenía muy profundas relaciones con Paraguay, Salta y Tucumán, que quedaron del otro lado de la frontera boliviana. También cabe señalar las vinculaciones entre Cuenca y Loja con Piura y Cajamarca, cuya relación mantiene hasta la actualidad una viva intensidad. Así mismo, distintos espacios amazónicos mantuvieron una estrecha vinculación con los dominios del Brasil, la cual consolidó ejes de intercambio que alcanzaron altos niveles de autonomía, incluso después de la fundación republicana.

intervinieron, y de manera decisiva, muchos peruanos. Además, lo cierto es que, para Santiago, la cuestión era más un asunto de supervivencia, conforme lo planteó Diego Portales - citado por el propio Burr-, al decir que la campańa contra la Confederación era como "una segunda independencia de Chile" (Burr, 1965, pp. 33 y 38). 


\section{Política exterior regional}

Para terminar, conviene preguntarse cuál fue la respuesta que estas jóvenes repúblicas ensayaron para hacer frente a este amplio conjunto de desafíos. Si bien se trata de un aspecto de la historia poco trabajado y existe un amplio margen para la discusión, considero que, para despejar esta interrogante, se debe reconocer el hecho de que todas ellas enfrentaron problemáticas comunes y que ninguna estuvo en condiciones de hacerles frente de manera individual. Consecuentemente, tal respuesta debería buscarse en el nivel del orden regional, que -como se ha venido señalando- tenía importantes particularidades, a pesar de haberse constituido a partir de los paradigmas westfalianos. En efecto, si bien la idea "sobre la naturaleza de los acuerdos justos y la distribución del poder" que dio forma a las relaciones entre los Estados republicanos surgidos luego de la independencia hispanoamericana estuvo alineada con los principios de derecho internacional que regulaban las relaciones entre las potencias europeas, no puede obviarse que, al compartir una vasta herencia histórica y cultural, abrazar los mismos principios fundacionales y haber sangrado juntos para alcanzar su independencia, el sentimiento de pertenecer a una misma comunidad que se había forjado desde fines del siglo XVIII tenía aún cabida en el imaginario político regional.

Teniendo presente lo anterior, se debe prestar atención a un factor que atravesaba de punta a punta este orden regional, debido a que se trataba de la mayor de las preocupaciones comunes entre todos sus componentes y a que formaba parte de la singularidad del orden regional de la independencia: la incertidumbre de la supervivencia. Esto -que, conforme a los principios westfalianos, se reconoce y respeta como un interés fundamental de carácter imperativo y no negociable para todas sus variables- no era un supuesto dado. De hecho, España no aceptaba la existencia de las 
nuevas repúblicas y su causa no carecía de respaldo entre las monarquías hereditarias europeas que venían de vencer a la Francia revolucionaria.

En las circunstancias de precariedad política, económica y social que se han descrito, la posibilidad de enviar una expedición restauradora representaba una amenaza creíble y ninguna de las repúblicas independientes tenía cómo enfrentarla. Los casos de Santo Domingo y México, que llegaron a ser invadidos - por Espańa, el primero, y por Francia y Estados Unidos, el segundo-, al igual que las tremendas dificultades en las que se vio el Perú para lidiar con la agresividad de una "expedición científica" española en la década de 1860 -aun después de la consolidación republicana posterior al gran auge guanero-, son una clara muestra de la tremenda vulnerabilidad de la región. Realmente no se sabe qué habría sucedido si Estados Unidos, ya en el camino hacia una franca prosperidad, no hubiera advertido a las potencias europeas que no toleraría una intervención extranjera en el continente americano. En efecto, si bien existen muchos asuntos que discutir en torno a la Doctrina Monroe, no debería caber duda de que, en su momento, fue crucial para dar un respiro vital a la existencia de las repúblicas hispanoamericanas en aquellos ańos tan difíciles.

La cuestión de la seguridad, apremiante en razón de la existencia de amenazas serias e inminentes, definió una de las tendencias de política exterior históricamente más destacables en la región y que la distinguen de otros espacios de relacionamiento: la búsqueda de la unidad a partir de la solidaridad. Naturalmente, esta tendencia se vio fortalecida por el imaginario común al que se ha hecho referencia anteriormente, aun cuando las urgentes consideraciones de seguridad fueron sus principales motores. Subrayo este aspecto, porque al lado de expresiones retóricas de unidad, el énfasis en la seguridad se encuentra en todos y cada uno de los acuerdos fir- 
mados en la región, ya sea bilaterales o multilaterales, generales o específicos, abiertos o cerrados, e independientemente de que hayan sido ratificados o no, a lo largo del medio siglo que siguió a la independencia. Por ejemplo, el Perú acordó, en 1822, un tratado con Colombia y otro con Chile, en los que se lee fraseos casi idénticos acerca de que estos países se "unen, ligan y confederan desde ahora y para siempre" a efecto de sostener su independencia "de la nación española o de cualquier otra dominación extranjera”, y añaden una serie de artículos referidos a la cooperación militar y naval (De la Reza, 2010, pp. 11-14 y 24-28).

La iniciativa más importante en este sentido fue la convocatoria al Congreso de Panamá. Los tratados mencionados se suscribieron, precisamente, siguiendo la estela de la invitación hecha por Bolívar en enero de 1822 para formar "una nación de repúblicas" (De la Reza, 2010, p. 4). La idea -como se sabe- fue establecer una federación de alcance continental, siguiendo el ejemplo norteamericano, alternativa que no prosperó. Al final no solo no acudieron todos los convocados, sino que ninguno de los acuerdos entró en vigor. Mucho se ha debatido al respecto, dado que la iniciativa se ha vinculado de manera unidireccional a la inspiración del Libertador caraqueño y se la señala, además, como un fracaso. Sin embargo, atendiendo a todo lo dicho en estas páginas, bien podría decirse lo contrario, dado que fue la respuesta más duradera de la región ante la compleja situación en la que sus repúblicas surgieron en la historia y los formidables desafíos que debieron enfrentar en aquel período. En primer lugar, porque, aun reconociendo que la reunión de Panamá se hizo a instancias de Bolívar y que los ausentes a la reunión habrían declinado asistir justamente por tal motivo, se debería recordar que, cuando se celebró, en 1826, la influencia de esta prominente figura de la independencia regional iniciaba su declive. Es decir, los participantes, entre los que contamos a México y a los países 
de Centroamérica, habrían ido a Panamá no por seguir la ruta trazada en la invitación original, sino animados por intereses propios que les eran comunes: consolidar la independencia, defenderla y establecer las bases y principios que regirían sus relaciones futuras, aspectos esenciales de su futura supervivencia.

Se podría admitir la idea del fracaso si el análisis se limita a constatar que de Panamá no surgió ninguna confederación; pero, si todo esto se observa desde una perspectiva más amplia, sería posible arribar a una conclusión muy diferente. La reunión de Panamá, al mismo tiempo que atendió las urgencias inmediatas de las nacientes repúblicas, expresó una voluntad mucho más amplia que la visión de una sola persona, pues se inserta en una idea anterior de pertenencia a una misma comunidad, la cual, si bien no encontró mecanismos viables para traducirse en realidad, definió al ideal unitario y a la solidaridad como elementos clave en la estructuración del orden regional. De hecho, desde la perspectiva de la teoría clásica de las relaciones internacionales evocada al comenzar, sería fácil sostener que la reunión de Panamá fracasó, debido a que primó el interés nacional sobre la solidaridad. Sin embargo, esta herramienta no alcanza para explicar desde una perspectiva histórica por qué se insistió tanto en este asunto en los diferentes congresos americanistas que se sucedieron a lo largo de medio siglo y por qué, hasta la actualidad, los diversos mecanismos de integración que se han venido diseñando e implementando en la región -más allá de su pertinencia o viabilidad- han seguido invocando la misma retórica de unidad y que esta sea tan aceptada en las diversas escalas de lo social. Se requiere, obviamente, mucho más que la dinámica de poder para entender el orden regional de la independencia, marcado tanto por el idealismo como por los complejos desafíos en medio de los que surgió. 
Recibido: 20 de agosto de 2020

Aprobado: 20 de noviembre de 2020

\section{Bibliografía}

Bolívar, S.

(1992) Obras completas. Vol. 2. Maveco de Ediciones S. A.

Braudel, F.

(1979) Civilisations matétrielle, économie et capitalisme. XVeXVIIIe siècle. Vol. 3. Le temps du monde. Armand Colin.

Burr, R. N.

By Reason or Force. Chile and the Balancing of Power in South America, 1830-1905. University of California Press, Ltd.

Buzan, B. y Little, R.

(2000) International Systems in World History. Remaking the studys of international relations. Oxford University Press.

Céspedes del Castillo, G.

(1999) Ensayos sobre los reinos castellanos de Indias. Real Academia de la Historia.

Cipolla, C.

(1999) La odisea de la plata española. Crítica.

Collier, S. y Sater, W. F.

(2004)

A History of Chile, 1808-2002. Cambridge University Press.

Contreras, C.

(2004) El aprendizaje del capitalismo. Estudios de historia económica y social del Perú republicano. Instituto de Estudios Peruanos. 
De la Reza, G.

(2010) Documentos sobre el Congreso Anfictiónico de Panamá. Fundación Biblioteca Ayacucho y Banco Central de Venezuela.

Elliot, J. H.

(2018) España y su mundo (1500-1700). Taurus.

Evans, R. J.

(2017)

La lucha por el poder. Europa 1815-1914. Planeta.

Findlay, R. y O'Rourke, K. H.

(2009) Power and Plenty. Trade, War, and the World Economy in the Second Millennium. (619 ed.) Princenton University Press.

Fisher, J.

(1982) "Monarquismo, regionalismo y rebelión en el Perú colonial, 1808-1815”. Historia y Cultura. Revista del Museo Nacional de Historia, (15), 117-139.

Garavaglia, J. C. y Marchena, C.

(2005) América Latina. De los origenes a la independencia. Vol. 1. América precolombina y la consolidación del espacio colonial. Crítica.

Gellner, E.

(1999) Nations et Nationalisme. Payot \& Rivages.

Guerra, F.-X.

126 (1993) Modernidad e independencias. Ensayos sobre las revoluciones hispánicas. Fondo de Cultura Económica.

Hobsbawm, E.

(1991) La era de la revolución (1789-1848). Labor Universitaria.

Kissinger, $\mathrm{H}$.

(2014) World Order. Penguin. 
Klooster, W.

(2009) Revolutions in the Atlantic world. A Comparative History. New York University Press.

Liss, P. K.

(1995) Los imperios trasatlánticos. Las redes del comercio y de las revoluciones de independencia. Fondo de Cultura Económica.

Lynch, J.

(2010) Simón Bolivar. Crítica.

Lynch, J.

(1989) Las revoluciones hispanoamericanas 1808-1826. Ariel.

Marks, R.

(2007)

Los origenes del mundo moderno. Una nueva visión. Crítica.

Miller, J.

(1975) Memorias del general Miller al servicio de la República del Perú. Vol. 1. Editorial Arica S. A.

Morgenthau, H. J.

(2007) Politics Among Nations. The Struggle for Power and Peace (7 ed.). McGraw-Hill.

Peralta Ruiz, V.

(2007) "Entre la fidelidad y la incertidumbre. El virreinato del Perú entre 1808 y 1810”. En M. Chust (Coord.), La eclosión juntera en el mundo hispano (pp. 138161). Fondo de Cultura Económica y El Colegio de México.

Pomeranz, K.

(2000)

The Great Divergence. China, Europe, and the Making of the Modern World Economy. Princenton University Press. 
Porras Barrenechea, R. y Wagner de Reyna, A.

(1997) Historia de los limites del Perú. Fondo Editorial del Ministerio de Relaciones Exteriores del Perú.

Reid, M.

(2017) Forgotten Continent. A History of the New Latin America. Yale University Press.

Rodríguez, J.

(2007)
"El Reino de Quito, 1808-1810". En M. Chust (Coord.), La eclosión juntera en el mundo hispano (pp. 162-191). Fondo de Cultura Económica y El Cole- gio de México.

Romano, R.

"Fundamentos del funcionamiento del sistema económico colonial”. En H. Bonilla (Coord.), El sistema colonial en la América española, pp. 239-280. Crítica.

Schaub, J.-F.

"The Imperial Question in the History of IberoAmerica: The Importance of the Long View". En K. Nicolaïdis, B. Sébe, y G. Maas (Eds.), Echoes of Empire. Memory, identity and colonial legacies (pp. 6380). I. B. Tauris \& Co. Ltd.

Schroeder, P. (2004)

Systems, Stability, and Statecraft. Essays on the International History of Modern Europe. Palgrave Macmillan.

128 Schroeder, P.

(2010)

"Not Even for the Seventeenth and Eighteenth Cen-
turies: Power and Order in the Early Modern Era".
En R. May, R. Rosecrance, y Z. Steiner (Eds.), His-
tory and Neorealism, (pp. 78-102). Cambridge Uni-
versity Press. 
Suárez, M.

(2009) El Perú en el mundo atlántico (1520-1739). En C. Contreras (Ed.), Compendio de historia económica del Perú. Economía del periodo colonial temprano, tomo 2, (pp. 229-311). Banco Central de Reserva e Instituto de Estudios Peruanos.

Stearns, P. N.

The Industrial Revolution in World history. Westview Press.

Szeminski, J.

¿Por qué matar a los españoles? Nuevas perspectivas sobre la ideología andina de la insurrección en el siglo XVIII. En S. J. Stern (Comp.), Resistencia, rebelión y conciencia campesina en los Andes. Siglos XVIII al XX, (pp. 164-168). Instituto de Estudios Peruanos.

Vollmer, G. (1965)

Bevölkerungspolitik und Bevölkerungsstruktur im Vizekönigreich Peru zu der Kolonialzeit /1741-1821). (Tesis para optar el grado de doctor). Universidad de Colonia.

Walker, C.

(2014) The Tupac Amaru Rebellion. Harvard University Press.

Wallerstein, I.

(1979) El moderno sistema mundial. La agricultura capitalista y los orígenes de la economia-mundo europea en el siglo $X V I$, tomo I. Siglo XXI.

Waltz, K. N.

(1979) Theory of International Politics. Waveland Press, Inc. 
